Original article

Reprint

\title{
Comparative assessment of circulatory autonomic regulation in the patients with coronary artery bypass graft or valvular heart disease correction
}

\author{
Anton R. Kiselev' ${ }^{1}$ Kristina A. Wulf ${ }^{2}$, Vladimir A. Shvartz², Anatoly S. Karavaev², Ekaterina I. Borovkova ${ }^{3}$, \\ Olga L. Bokeria ${ }^{2}$ \\ ${ }^{1}$ Saratov State Medical University, Saratov, Russia \\ 2 A.N. Bakoulev National Medical Research Center for Cardiovascular Surgery, Moscow, Russia \\ 3 Saratov State University, Saratov, Russia
}

Received 1 February, 2018, Accepted 21 January, 2020

Original Text (C) Kiselev A.R., Vulf K.A., Shvartz V.A., Karavaev A.S., Borovkova E.I., Bockeria O.L., 2018, published in Saratov Journal of Medical Scientific Research 2018; 14 (1): 45-49.

(C) 2020, Kiselev A.R., Vulf K.A., Shvartz V.A., Karavaev A.S., Borovkova E.I., Bockeria O.L.

(C) 2020, Saratov Medical Journal

\begin{abstract}
:
The objective of our study was to investigate the features of circulatory autonomic regulation in the patients with a coronary artery bypass graft surgery (CABG) or correction of a valvular heart disease (CVHD).

Material and Methods. Our study enrolled 42 patients (including 12 women) aged 63 (57; 67), who underwent CABG; and 36 patients (including 16 women) aged 58 (47; 65), who underwent CVHD. Simultaneous 15-minute recordings of electrocardiograms and photoplethysmograms (PPG) were performed on all patients before and after the surgery. We assessed and analyzed statistical and frequency-related measures of heart rate variability (HRV) and index of synchronization (S) among low-frequency (LF) oscillations in HRV and PPG.

Results. The values of most autonomic regulation indices in our study did not have statistically significant differences among the patients with CABG and CVHD at all stages of research. The exception was represented by the heart rate, which was higher before CVHD ( $\mathrm{p}=0.013)$.

Conclusion. In all patients with CABG, the values of HRV and S did not depend on the differences in their clinical statuses or performed cardiac surgical interventions.
\end{abstract}

Keywords: cardiovascular autonomic control, coronary artery bypass graft surgery, valvular heart disease, heart rate variability.

Cite as Kiselev AR, Wulf KA, Shvartz VA, Karavayev AS, Borovkova EI, Bokeria OL. Comparative assessment of circulatory autonomic regulation in the patients with coronary artery bypass graft or valvular heart disease correction. Saratov Medical Journal 2020; 1(1): eo101

Correspondence to Anton R. Kiselev. Tel.: (8452)669873. E-mail: kiselev@cardio-it.ru

\section{Introduction}

Heart rate variability (HRV) has recently become a conventional study object in cardiac surgery patients [1]. Available clinical evidence regarding prognostic significance of HRV indices in such patients is somewhat contradictory. While some study results indicated an increased risk of lethal outcomes of coronary artery bypass surgery (CABG) in the patients with reduced HRV [2], other data implied no connection between the indices of vegetative dysfunction and the prognosis in cardiac surgery patients [3]. Besides HRV, the researchers' attention was attracted by blood pressure variability (BPV), characterizing autonomic regulation processes in the cardiovascular system [4]. In our earlier publications, we used the evaluation of synchronization of low-frequency (LF) oscillations in HRV and the photoplethysmogram (PPG) signal to study an interaction between baroreceptor reflex mechanisms of circulatory autonomic regulation [5]. It was established that cardioplegia, widely used for various cardiac surgeries, was increasing the risk of postoperative complications [6]. At the same time, the effect of cardioplegia and other cardiac operative procedures on the autonomic regulation of the cardiovascular system remained virtually unexplored.

The objective of our study was to investigate the features of circulatory autonomic regulation in the patients who underwent coronary artery bypass graft surgery (CABG) or correction of valvular heart disease (CVHD).

\section{Material and methods}

Our study included 42 patients (29\% of those women) aged $63(57 ; 67)$ years old (the data are presented as medians and interquartile range - Me), who underwent CABG surgery and 36 patients ( $44 \%$ of those women) aged $58(47 ; 65)$, who underwent CVHD. All patients were subjected to full clinical examination, medicated treatment and cardiac surgery (CABG or CVHD) in conditions of artificial blood circulation $(\mathrm{ABC})$. CABG was performed on working hearts, while cardioplegia was used for $\mathrm{CVH}$. 
Table 1. Clinical and anamnestic characteristics of the patients in the study groups

\begin{tabular}{|c|c|c|c|}
\hline \multirow[t]{2}{*}{ Indicators } & \multicolumn{2}{|c|}{ Groups of patients } & \multirow[t]{2}{*}{$\mathrm{p}$} \\
\hline & $\begin{array}{l}\text { CABG } \\
(\mathrm{n}=42)\end{array}$ & CVHD (n=36) & \\
\hline $\begin{array}{l}\text { Age, years, median and } \\
\text { interquartile range } \quad(25 \% \text {; } \\
75 \%)\end{array}$ & $63(57 ; 67)$ & $58(47 ; 65)$ & 0,086 \\
\hline Females, \% & 29 & 44 & 0,152 \\
\hline $\begin{array}{l}\text { BMI, } \mathrm{kg} / \mathrm{m}^{2} \text {, median and } \\
\text { interquartile range } \quad(25 \% \text {; } \\
75 \%)\end{array}$ & $\begin{array}{l}29,2(27,3 ; \\
32,9)\end{array}$ & $25,6(23,2 ; 29,0)$ & 0,001 \\
\hline HA in the anamnesis, $\%$ & 71,4 & 0 & $<0,001$ \\
\hline Stroke in the anamnesis, $\%$ & 4,8 & 5,6 & 0,874 \\
\hline $\mathrm{AH}, \%$ & 95,2 & 50,0 & $<0,001$ \\
\hline Smoking, \% & 35,7 & 16,7 & 0,063 \\
\hline Diabetes, \% & 16,7 & 0 & 0,012 \\
\hline COPD, $\%$ & 7,1 & 0 & 0,107 \\
\hline PCI in the anamnesis, $\%$ & 19,0 & 0 & 0,007 \\
\hline $\begin{array}{l}\text { LVEF, \%, median and } \\
\text { interquartile range } \quad(25 \% \text {; } \\
75 \%)\end{array}$ & $60(55 ; 62)$ & $66(60 ; 67)$ & 0,001 \\
\hline $\begin{array}{l}\text { Blood creatinine (before } \\
\text { surgery), mg/dl, median } \\
\text { and interquartile range } \\
(25 \% ; 75 \%)\end{array}$ & $84(74 ; 105)$ & $69(61 ; 88)$ & 0,044 \\
\hline $\begin{array}{l}\text { Blood glucose (before } \\
\text { surgery), mmol/l, median } \\
\text { and interquartile range } \\
(25 \% ; 75 \%)\end{array}$ & $5,4(4,9 ; 6,2)$ & $5,0(4,7 ; 5,2)$ & 0,051 \\
\hline $\begin{array}{l}\text { Hematocrit (before } \\
\text { surgery), } \% \text {, median and } \\
\text { interquartile range ( } 25 \% \text {; } \\
75 \%)\end{array}$ & $41(38 ; 44)$ & $40(37 ; 42)$ & 0,779 \\
\hline ACEI (before surgery), $\%$ & 81,0 & 27,8 & $<0,001$ \\
\hline $\begin{array}{l}\text { Beta blockers (before } \\
\text { surgery), \% }\end{array}$ & 81,0 & 22,2 & $<0,001$ \\
\hline Statins (before surgery), $\%$ & 71,4 & 22,2 & $<0,001$ \\
\hline $\begin{array}{l}\text { Diuretics (before surgery), } \\
\%\end{array}$ & 35,7 & 44,4 & 0,436 \\
\hline CCB (before surgery), $\%$ & 23,8 & 5,6 & 0,029 \\
\hline Cardioplegia, \% & 0 & 100 & $<0,001$ \\
\hline $\begin{array}{l}\text { Duration of } A B C, \text { minutes, } \\
\text { median and interquartile } \\
\text { range }(25 \% ; 75 \%)\end{array}$ & $73(56 ; 98)$ & $124(102 ; 145)$ & $<0,001$ \\
\hline $\begin{array}{l}\text { Duration of postoperative } \\
\text { ALV, hours, median and } \\
\text { interquartile range (25\%; } \\
75 \%)\end{array}$ & $\begin{array}{l}13,5(9,0 \\
21,5)\end{array}$ & $20,0(13,0 ; 25,0)$ & 0,099 \\
\hline $\begin{array}{l}\text { Length of stay in a hospital, } \\
\text { days, median and } \\
\text { interquartile range ( } 25 \% \text {; } \\
75 \%)\end{array}$ & $7,5(7,0 ; 8,0)$ & $8,0(7,0 ; 11,0)$ & 0,085 \\
\hline $\begin{array}{l}\text { Nosocomial complications, } \\
\%\end{array}$ & 16,7 & 38,9 & 0,039 \\
\hline
\end{tabular}

$\mathrm{M} \pm \mathrm{SD}$ - mean and standard deviation; median and interquartile range range $(25 \% ; 75 \%)$ - median and interquartile range range ; BMI - body mass index; HA - heart attack (myocardial infarction); AH - Arterial Hypertension; COPD - chronic obstructive pulmonary disease; PCI - percutaneous coronary intervention; LVEF - left ventricular ejection fraction; ACEI - of angiotensin-convertingenzyme inhibitors; CCB - calcium channel blockers; ABC - artificial blood circulation; ALV - artificial lungs ventilation.

All patients gave their voluntary informed consent to participate in the study. The design of the study was approved by the ethical committee of A.N. Bakoulev National Medical Research Center for Cardiovascular Surgery, Russian Federation Ministry of Healthcare
The exclusion criteria encompassed heart rhythm disturbances impeding HRV analysis, severe heart failure, cardiomyopathy, endocrine diseases (except for compensated diabetes), cancer, stroke, mental illness, microcirculation disorders, and secondary arterial hypertension.

General clinical characteristics of the patients in the study groups are presented in Table 1. Patients with CABG had a higher level of body mass index, diastolic pressure, blood creatinine, as well as much higher frequency of previous myocardial infarction, diabetes mellitus and arterial hypertension. Patients after CVHD were characterized by higher left ventricular ejection fraction, longer duration of intraoperative use of the cardiopulmonary bypass and a slightly increased frequency of nosocomial complications. We also detected some differences in patient groups under examination in terms of frequencies of certain types of medication prescriptions.

We conducted simultaneous 15-minute electrocardiogram (ECG) and FPG recordings with $250 \mathrm{~Hz}$ frequency of discretization from the index finger of all patients before and 5-7 days after a surgery. The patients were in a supine position and breathed spontaneously. Recordings containing significant breath holding, extrasystoles, and a prominent linear trend were not included in the subsequent analysis.

We evaluated statistical and frequency-related indicators of heart rate variability (HRV) and the synchronization index of low-frequency (LF) oscillations in HRV and PPG (S-index). The $\mathrm{S}$ index (proportion of time expressed as a percentage of the total recording of biological signals, during which the low-frequency oscillations were synchronous among themselves) was computed in accordance with the previously proposed original method [5].

Besides, the following HRV indicators were calculated [7]: average heart rate (HR, bpm); SDNN (ms); total spectrum power of $\mathrm{HRV}$ in the frequency range $\mathrm{o}-0.50 \mathrm{~Hz}(\mathrm{TP}, \mathrm{ms} 2)$; the ratio of the low-frequency power range $(0.04-0.15 \mathrm{~Hz})$ to the total spectrum power of HRV, expressed as a percentage (LF\%); the ratio of the high-frequency (HF) power range $(0.15-0.40 \mathrm{~Hz})$ to the total spectrum power of HRV, expressed as a percentage (HF\%); power ratio of $\mathrm{LF}$ to $\mathrm{HF}$ ranges of HRV spectrum (LF / HF).

Statistical analysis was conducted with Statistica 6.1 (StatSoft, USA) software package. Quantitative data were presented in the form of a median and interquartile range Me $(25 \% ; 75 \%)$, qualitative data were presented in the form of ratios (frequencies), expressed as percentages. We used non-parametric statistical methods. The comparison of the groups, due to the fact that significant part of the indicators did not comply with a normal distribution, was conducted with a Mann-Whitney criterion. Comparison of frequencies was made using the t-test. Statistical significance of evaluations and comparisons was taken at the level above $95 \%$.

\section{Results}

Among the indicators of circulatory autonomic regulation (both initially and 5-7 days after surgery) in the two groups, the difference was revealed only at the level of average HR before surgery, that was higher in patients undergoing surgical CVHD, than in the CABG group ( $\mathrm{p}=0.013)$ (Table 2). At that, there was a marked intra-group variability of values of the majority of vegetative indicators under study in both groups of patients, which manifests itself in a rather wide range between the minimum and maximum values of 
the indicators, as well as the size of the interquartile range (Table 2). After cardiac surgery operations there was a significant $(p<0.05)$ decline in a number of vegetative regulation indicators: SDNN, TP and LF / HF.

\section{Discussion}

CABG surgery is associated with a HRV decrease at early post-operative stage, which lowers the significance of using HRV indicators for evaluating a long-term risk of developing cardiovascular complications [3, 9]. However, some scientists have previously reported high predictive power of non-linear HRV assessment for postoperative risk in the patients who underwent this type of cardiac surgery [10, 11].

The total reduction of HRV in the patients with CVHD is due to baroreceptor reflex dysfunction in conjunction with a hemodynamic failure of the venous heart $[12,13]$, which can be corrected via surgery.

We observed total HRV decrease in postoperative period for most patients after the surgery under artificial circulation condition (CABG or CVHD), which supported the results of other studies [12-15]. Such decrease in HRV was probably due multiple factors: artificial circulation and the features of a cardiac surgery (anesthesia, duration of postoperative artificial lung ventilation, cardioplegia and others) $[14,16$, and 17].

However, the mechanisms of these impacts on the autonomic regulation of the cardiovascular system are still poorly studied [18-20]. However, the differences in clinical status among the groups of cardiac surgery patients in our study (Table 1) did not cause group differences in circulatory autonomic regulation vegetative indicators (Table 2), which is remarkable because the influence of many clinical characteristics on HRV (in particular, age, body mass index, heart attack rate, systolic function condition of the left ventricle, beta-blocker therapy, etc.) has been previously proved [7]. Additional assessment of the mechanisms of systemic circulatory autonomic regulation can be completed on the basis of synchronization evaluation of the lowfrequency fluctuations in HRV and PPG [5]. This approach has previously demonstrated good predictive power for personalized cardiovascular risk assessment [5]. The present study did not discover significant differences in the values of this indicator before and after the surgery in both groups of the patients under study (see Table 2; p> 0.05).

\section{Conclusion}

Save for average HR levels, no differences among the patients after CABG vs. CVHD surgery were found in synchronization index values of the LF oscillations in their cardiovascular system and in most HRV-related indicators of our study (SDNN, TP, LF\%, HF\%, LF/HF).

\section{Conflict of interest}

The research project has been supported by the Russian Foundation for Fundamental Research grant No. 17-34-50026mol_nr.
Table 2. Indicator values of circulatory autonomic regulation in the patients of the study groups before and after cardiac surgery

\begin{tabular}{|c|c|c|c|}
\hline \multirow[t]{2}{*}{ Indicators } & \multicolumn{2}{|c|}{ Groups of patients } & \multirow[t]{2}{*}{$\mathrm{p}$} \\
\hline & CABG $(n=42)$ & CVHD (n=36) & \\
\hline \multicolumn{4}{|c|}{ Before surgery } \\
\hline S, \% & $24,7(18,3 ; 35,2)$ & $22,5(13,4 ; 27,4)$ & 0,400 \\
\hline $\begin{array}{ll}\text { Heart rate, } \\
\text { bpm }\end{array}$ & $67(60 ; 72)$ & $69(65 ; 80)$ & 0,013 \\
\hline SDNN, ms & $34,9(24,9 ; 52,3)$ & $37,7(28,4 ; 53,1)$ & 0,903 \\
\hline $\mathrm{TP}, \mathrm{ms}^{2}$ & $493(311 ; 1247)$ & $425(246 ; 969)$ & 0,696 \\
\hline $\mathrm{LF} \%$ & $24,4(16,5 ; 34,6)$ & $29,4(17,1 ; 36,9)$ & 0,653 \\
\hline HF\% & $21,6(9,5 ; 47,0)$ & $20,2(11,1 ; 29,7)$ & 0,422 \\
\hline $\mathrm{LF} / \mathrm{HF}$ & $1,2(0,6 ; 2,7)$ & $1,4(0,6 ; 2,9)$ & 0,546 \\
\hline \multicolumn{4}{|c|}{ 5-7 days after surgery } \\
\hline $\mathrm{S}, \%$ & $20,3(10,2 ; 27,5)$ & $20,2(15,5 ; 28,1)$ & 0,529 \\
\hline $\begin{array}{l}\text { Heart rate, } \\
\text { bpm }\end{array}$ & $78(73 ; 87)$ & $74(66 ; 90)$ & 0,439 \\
\hline SDNN, ms & $15,6(11,3 ; 41,0)$ & $18,0(11,1 ; 71,9)$ & 0,479 \\
\hline $\mathrm{TP}, \mathrm{ms}^{2}$ & $84(26 ; 496)$ & $125(36 ; 2735)$ & 0,326 \\
\hline $\mathrm{LF} \%$ & $26,6(18,1 ; 36,4)$ & $30,8(21,8 ; 39,8)$ & 0,526 \\
\hline HF\% & $26,3(10,8 ; 46,4)$ & $23,7(9,7 ; 43,4)$ & 0,637 \\
\hline $\mathrm{LF} / \mathrm{HF}$ & $0,8(0,5 ; 3,4)$ & $1,2(0,6 ; 2,9)$ & 0,586 \\
\hline
\end{tabular}

Data is presented in the form of the median and interquartile range (25\%; 75\%). 


\section{References}

1. Lakusic N, Mahovic D, Kruzliak P, et al. Changes in heart rate variability after coronary artery bypass grafting and clinical importance of these findings. Bio Med Research International 2015; 2015: 680515. https://doi.org/10.1155/2015/680515

2. Lakusic N, Mahovic D, Sonicki Z, et al. Outcome of patients with normal and decreased heart rate variability after coronary artery bypass grafting surgery. Int $J$ Cardiol 2013; 166: 516-518.

3. Milicevic G, Fort L, Majsec M, et al. Heart rate variability decreased by coronary artery surgery has no prognostic value. Eur J Cardiovasc Prev Rehabil 2004; 11: 228-232.

http://dx.doi.org/10.1097/01.hjr.0000129743.53464.co

4. Souza Neto EP, Loufouat J, Saroul C, et al. Blood pressure and heart rate variability changes during cardiac surgery with cardiopulmonary bypass. Fundam Clin Pharmacol 2004; 18: 387-396. http://dx.doi.org/10.1111/j.1472-8206.2004.00244.x

5. Kiselev AR, Karavaev AS, Gridnev VI, et al. Method of estimation of synchronization strength between low-frequency oscillations in heart rate variability and photoplethysmographic waveform variability. Russ Open Med J 2016; 5: e0101.

http://dx.doi.org/10.15275/rusomj.2016.0101

6. Weman SM, Karhunen PJ, Penttila A, et al. Reperfusion injury associated with one-fourth of deaths after coronary artery bypass grafting. Ann Thorac Surg 2000; 70: 807-812.

https://pubmed.ncbi.nlm.nih.gov/11016314/

7. Task Force of the European Society of Cardiology and the North American Society of Pacing and Electrophysiology. Heart rate variability: standards of measurement, physiological interpretation, and clinical use. Circulation 1996; 93: 1043-1065. https://www.escardio.org/static-

file/Escardio/Guidelines/Scientific-Statements/guidelinesHeart-Rate-Variability-FT-1996.pdf

8. Huikuri HV, Stein PK. Heart rate variability in risk stratification of cardiac patients. Prog Cardiovasc Dis 2013; 56: 153-159. http://dx.doi.org/10.1016/j.pcad.2013.07.003

9. Stein PK, Domitrovich PP, Kleiger RE; CAST Investigators. Including patients with diabetes mellitus or coronary artery bypass grafting decreases the association between heart rate variability and mortality after myocardial infarction. Am Heart J 2004; 147: 309-316.

http://dx.doi.org/10.1016/s0002-8703(03)00520-9

10. Laitio T, Huikuri H, Kentala E, et al. Correlation properties and complexity of perioperative RR-interval dynamics in coronary artery bypass surgery patients. Anesthesiology 2000; 93: 69-80. http://dx.doi.org/10.1097/00000542-200007000-00015

11. Godoy MF de, Takakura IT, Correa PR, et al. Preoperative nonlinear behavior in heart rate variability predicts morbidity and mortality after coronary artery bypass graft surgery. Med Sci Monit 2009; 15: CR117-CR122.

https://www.pubfacts.com/detail/19247242/Preoperativenonlinear-behavior-in-heart-rate-variability-predicts-morbidityand-mortality-after-cor

12. Finley JP, Nugent ST, Hellenbrand W, et al. Sinus arrhythmia in children with atrial septal defect: an analysis of heart rate variability before and after surgical repair. Br Heart $J$ 1989; 61: 280-284. https://pubmed.ncbi.nlm.nih.gov/2930665/

13. Bakari S, Koca B, Oztunc F, Abuhandan M. Heart rate variability in patients with atrial septal defect and healthy children. $J$ Cardiol 2013; 61: 436-439. http://dx.doi.org/10.1016/j.jjcc.2013.01.014

14. Hogue CW Jr, Stein PK, Apostolidou I, et al. Alterations in temporal patterns of heart rate variability after coronary artery bypass graft surgery. Anesthesiology 1994; 81: 1356-1364. https://doi.org/10.1097/00000542-199412000-00009
15. Demirel S, Akkaya $\mathrm{V}$, Oflaz $\mathrm{H}$, et al. Heart rate variability after coronary artery bypass graft surgery: a prospective 3-year followup study. Ann Noninvasive Electrocardiol 2002; 7: 247-250. http://dx.doi.org/10.1111/j.1542-474x.2002.tbo0171.x

16. Bronner F, Douchet MP, Quiring E, et al. Variability of heart rate after heart surgery under extracorporeal circulation: aortocoronary bypass or aortic valve replacement. Ann Cardiol Angeiol (Paris) 1998; 47: 549-554.

17. Lakusic N, Slivnjak V, Baborski F, Cerovec D. Heart rate variability after off-pump versus on-pump coronary artery bypass graft surgery. Cardiol Res Pract 2009; 2009: 295376. http://dx.doi.org/10.4061/2009/295376

18. Chamchad D, Horrow JC, Samuels LE, et al. Heart rate variability measures poorly predict atrial fibrillation after offpump coronary artery bypass grafting. J Clin Anesth 2011; 23 451-455. http://dx.doi.org/10.1016/i.jclinane.2010.12.01611

19. Hakala T, Pitkanen O, Hippelainen M. Feasibility of predicting the risk of atrial fibrillation after coronary artery bypass surgery with logistic regression model. Scand J Surg 2002; 91: 339-344. http://dx.doi.org/10.1080/14017430310021418

20. Ksela J, Suwalski P, Kalisnik JM, et al. Assessment of nonlinear heart rate dynamics after beating-heart revascularization. Heart Surg Forum 2009; 12: E10-E16.

http://dx.doi.org/10.1532/HSF98.20081116

\section{Authors:}

Anton R. Kiselev - DSc, Principal Research Scientist, Division of Novel Information Technology Advances in Cardiology, Research Institute of Cardiology, Saratov State Medical University, Saratov, Russia;

Kristina A. Wulf - Post-graduate student, Division for Surgical Treatment of Interactive Pathology, A.N. Bakoulev National Medical Research Center for Cardiovascular Surgery, Moscow, Russia;

Vladimir A. Shvartz - PhD, Research Scientist, Division for Surgical Treatment of Interactive Pathology, A.N. Bakoulev National Medical Research Center for Cardiovascular Surgery, Moscow, Russia;

Anatoly S. Karavaev - PhD, Assistant Professor, Department of Dynamic Modeling and Biomedical Engineering, Saratov State University, Saratov, Russia;

Ekaterina I. Borovkova - Instructor, Department of Dynamic Modeling and Biomedical Engineering, Saratov State University, Saratov, Russia;

Olga L. Bokeria - DSc, Professor, Corresponding Member of the Russian Academy of Sciences, Lead Research Scientist, Division for Surgical Treatment of Interactive Pathology, A.N. Bakoulev National Medical Research Center for Cardiovascular Surgery, Moscow, Russia. 